\title{
Normative Perceptions of Cannabis Use Among European University Students: Associations of Perceived Peer Use and Peer Attitudes With Personal Use and Attitudes
}

\author{
ROBERT C. DEMPSEY, PH.D., ${ }^{a, b, *}$ JOHN MCALANEY, PH.D., ${ }^{c}$ STEFANIE M. HELMER, PH.D., ${ }^{d}$ CLAUDIA R. PISCHKE, PH.D. ${ }^{d}$ \\ YILDIZ AKVARDAR, PH.D., M.D., ${ }^{e}$ BRIDGETTE M. BEWICK, PH.D.,${ }^{f}$ HELEN J. FAWKNER, PH.D.,,${ }^{g}$ \\ FRANCISCO GUILLEN-GRIMA, M.B.A., M.P.H., M.SC., PH.D., M.D., ${ }^{h}$ CHRISTIANE STOCK, PH.D. ${ }^{i}$ BART VRIESACKER, M.SC., ${ }^{j}$ \\ GUIDO VAN HAL, PH.D., ${ }^{j}$ FERDINAND SALONNA, PH.D.,,${ }^{k}$ ONDREJ KALINA, PH.D., ${ }^{l}$ OLGA OROSOVA, PH.D., ${ }^{l}$ \\ \& RAFAEL T. MIKOLAJCZYK, M.D., M.SC. ${ }^{m}$ \\ ${ }^{a}$ Division of Psychology, University of Bradford, Bradford, West Yorkshire, United Kingdom \\ ${ }^{b}$ Centre for Health Psychology \& Staffordshire Centre for Psychological Research, School of Psychology, Sport and Exercise, Staffordshire \\ University, Stoke-on-Trent, Staffordshire, United Kingdom \\ ${ }^{c}$ Department of Psychology, Bournemouth University, Bournemouth, Dorset, United Kingdom \\ ${ }^{d}$ Leibniz Institute for Prevention Research and Epidemiology (BIPS), Bremen, Germany \\ eDepartment of Psychiatry, Marmara University Medical School, Istanbul, Turkey \\ ${ }^{f}$ Academic Unit of Psychiatry and Behavioural Sciences, Leeds Institute of Health Sciences, School of Medicine, University of Leeds, Leeds, \\ United Kingdom \\ gSchool of Social, Psychological \& Communication Sciences, Leeds Beckett University, Leeds, United Kingdom \\ ${ }^{h}$ Department of Health Sciences, Public University of Navarra, Navarra, Spain \\ ${ }^{i}$ Unit for Health Promotion Research, University of Southern Denmark, Esbjerg, Denmark \\ ${ }^{j}$ Medical Sociology and Health Policy, University of Antwerp, Antwerp, Belgium \\ ${ }^{k}$ Institute of Active Lifestyle, Palacky University of Olomouc, Olomouc, Czech Republic \\ ${ }^{l}$ Department of Educational Psychology and Health Psychology, PJ Safarik University in Košice, Košice, Slovakia \\ ${ }^{m}$ Department of Epidemiology, Helmholtz Centre for Infection Research, Braunschweig, Germany
}

\begin{abstract}
Objective: Perceptions of peer behavior and attitudes exert considerable social pressure on young adults to use substances. This study investigated whether European students perceive their peers' cannabis use and approval of cannabis use to be higher than their own personal behaviors and attitudes, and whether estimations of peer use and attitudes are associated with personal use and attitudes. Method: University students $(n=4,131)$ from Belgium, Denmark, Germany, the Slovak Republic, Spain, Turkey, and the United Kingdom completed an online survey as part of the Social Norms Intervention for Polysubstance usE in students (SNIPE) Project, a feasibility study of a web-based normative feedback intervention for substance use. The survey assessed students' (a) personal substance use and attitudes and (b) perceptions of their peers' cannabis use (descriptive norms) and attitudes (injunctive
\end{abstract}

norms). Results: Although most respondents (92\%) did not personally use cannabis in the past 2 months, the majority of students thought that the majority of their peers were using cannabis and that their peers had more permissive attitudes toward cannabis than they did. When we controlled for students' age, sex, study year, and religious beliefs, perceived peer descriptive norms were associated with personal cannabis use (odds ratio $[\mathrm{OR}]=1.42 ; 95 \% \mathrm{CI}[1.22,1.64])$ and perceived injunctive norms were associated with personal attitudes toward cannabis use $(\mathrm{OR}=1.46$; $95 \%$ CI $[1.09,1.94])$. Conclusions: European students appear to possess similar discrepancies between personal and perceived peer norms for cannabis use and attitudes as found in North American students. Interventions that address such discrepancies may be effective in reducing cannabis use. (J. Stud. Alcohol Drugs, 77, 740-748, 2016)
G LOBALLY, CANNABIS IS THE MOST frequently used illicit substance (World Health Organization, 1997). Initiation of cannabis use typically occurs in late adolescence and early adulthood, a period in life that is also as-

Received: September 26, 2015. Revision: March 29, 2016.

The SNIPE study was funded by a grant from the European Commission, Directorate General Justice, Freedom and Security (JLS/2009-2010/DPIP/ AG). The SNIPE study is registered on the German Clinical Trials Register (ID: DRKS00004375).

*Correspondence may be sent to Robert C. Dempsey at the Centre for Health Psychology, School of Psychology, Sport and Exercise, Faculty of Health Sciences, Staffordshire University, Science Centre, Leek Road, Stokeon-Trent, ST4 2DF, United Kingdom, or via email at: robert.dempsey@staffs. ac.uk. sociated with the peak of cannabis usage (Degenhardt et al., 2008; Degenhardt \& Hall, 2012). After alcohol and tobacco, cannabis is one of the most commonly used substances by university students (Arbour-Nicitopoulos et al., 2010; Webb et al., 1996). Indeed, young adulthood and studying at university have been identified as periods in which there is a potential high exposure to illicit substances and the opportunity to use substances (Arria et al., 2008). The exact rates of cannabis use by students can also differ between countries, with higher rates of use noted in more developed nations (Hall \& Degenhardt, 2009; Smart \& Ogborne, 2000). Cannabis use by university students is typically heaviest in the first year of study and tends to decrease over the course of academic studies and in the years after graduation (Cal- 
deira et al., 2008). Nevertheless, students who develop and maintain regular cannabis use before university, or during their studies, are more likely to use cannabis at a heavy rate in their post-university life and are at a heightened risk of various negative mental and physical health outcomes (Caldeira et al., 2012).

Negative cannabis use outcomes include poor student academic attainment, executive and cognitive deficits, the use of other illicit substances, increased risk of respiratory impairments, physical injury, and driving under the influence of substances (Caldeira et al., 2008, 2012; Grant et al., 2012; Hall, 2009; Hall \& Degenhardt, 2009; Webb et al., 1996). Longer-term regular cannabis use can also be associated with the heightened risk of developing psychotic symptoms in students (Skinner et al., 2011), with the risk of experiencing psychotic symptoms increasing with heavier use (Moore et al., 2007). Young adults appear to be at a particularly high risk of engaging in heavy levels of cannabis use and experiencing adverse effects of using cannabis (Hall, 2009).

Compared with other substances, cannabis may be associated with largely transient negative consequences and with a number of perceived positive experiences, including increased relaxation, positive affect, enhanced sensory experiences, and creativity (Hall \& Degenhardt, 2009; Hammersley \& Leon, 2006). The lack of immediately experienced negative consequences could mean that some individuals who begin to use cannabis may not be initially discouraged from continued use. For young adults, the continued use of cannabis poses a significant risk to maintaining regular usage patterns that could lead some individuals to become cannabis dependent (Le Strat et al., 2009). Therefore, intervening early is necessary in order to prevent sustained and/or problematic levels of cannabis use by young adults, particularly university students, and the experience of associated negative outcomes (Caldeira et al., 2012).

The use of substances by influential peers is one of a number of social factors that can exert pressure on individuals to use substances (Hawkins et al., 1992). There is convergent evidence that students tend to overestimate their peers' substance use, in terms of the quantity and frequency of substance use (descriptive norms) and their peers' attitudes regarding the acceptability of substance use (injunctive norms) (e.g., Perkins et al., 1999). Research to date has largely focused on the role of normative perceptions on alcohol use, typically by North American students, with evidence to suggest that students tend to overestimate their peers' alcohol consumption and attitudes toward alcohol use (e.g., McAlaney et al., 2015; Neighbors et al., 2006; Perkins et al., 1999).

In terms of cannabis use, there is evidence that perceived peer norms are predictive of personal cannabis use (e.g., Lewis \& Clemens, 2008; Neighbors et al., 2008) and that students' perceptions that cannabis use is a normative behavior on campus are associated with an increased risk of use
(Page \& Scanlan, 2000). A number of studies have reported that university students tend to overestimate their peers' cannabis use (Arbour-Nicitopoulos et al., 2010; Bertholet et al., 2013; Franca et al, 2010; Kilmer et al., 2006; LaBrie et al., 2009; Martens et al., 2006; Page \& Roland, 2004; Perkins et al., 1999), with such overestimations associated with increased personal cannabis consumption among U.S. students (Buckner, 2013; LaBrie et al., 2009). There is also evidence that more frequent student users of cannabis tend to overestimate how often students at their university use cannabis (Kilmer et al., 2006; Page \& Roland, 2004). In addition to U.S. studies, overestimation of peer cannabis use has been associated with greater cannabis use in the last month in Swiss young males (Bertholet et al., 2013) and by French (Franca et al., 2010) and Canadian university students (Arbour-Nicitopoulos et al., 2010).

There is also evidence that students overestimate peer injunctive norms, perceiving that their peers are more approving of cannabis use than themselves (LaBrie et al., 2010), with such injunctive norm perceptions associated with increased usage among U.S. cannabis-using students (Neighbors et al., 2008). Students' own personal cannabis approval is strongly influenced by perceived injunctive norms of typical students, close friends, and parents, with personal approval then being a significant predictor of personal cannabis use (LaBrie et al., 2010). However, only the perceived approval of typical students and close friends had a direct effect on personal use in LaBrie et al.'s (2010) study, suggesting that perceived peer norms may be the more powerful influence on cannabis use. In addition, students may also underestimate their peers' experience of cannabis-related problems, with such underestimations associated with more personally experienced cannabis-related problems (Ecker et al., 2014). Furthermore, both perceived peer descriptive and injunctive norms have been associated with increased personal use (Ecker et al., 2014). Perceptions of peer cannabis use, attitudes, and associated experiences appear to be important influences in predicting personal cannabis use and attitudes; however, there is little research into the role of social norms perceptions on cannabis use in students from across Europe.

The presence of these misperceptions for alcohol and other substances has led to the development of the social norms approach as a means of early intervention (McAlaney et al., 2011). Interventions based on this approach attempt to address commonly held misperceptions of peer norms and reduce the perceived social pressure to engage in heavy consumption by providing feedback comparing students' perceptions of social norms at their university with actual campus norms (McAlaney et al., 2011). There is evidence that social norms-focused feedback interventions are effective in reducing student alcohol use and perceptions of peer norms (e.g., Neighbors et al., 2010). Although few social norms interventions have focused on reducing cannabis use, 
preliminary research has indicated the potential benefits of web-based personalized normative feedback on reducing perceived peer descriptive and injunctive cannabis use norms (Elliott \& Carey, 2012; Lee et al., 2010).

Research into the influence of social norms perceptions on student cannabis use has typically been limited to samples of students from North American universities, and there has been a lack of European studies into the associations between perceived peer norms and cannabis use. Findings from previous U.S. college student studies may not be wholly generalizable to European university students because of potential differences in regional, cultural, and local country cannabis use norms. Whether university students across Europe display similar discrepancies between their own personal cannabis use and personal attitudes with their perceptions of their peers' attitudes and cannabis usage is unclear. Nor is it known if such perceptions are associated with heavier use of cannabis and more permissive personal cannabis use attitudes in European university students.

The current study investigated the relationship between European university students' personal cannabis use and their perceptions of cannabis use among their student peers. The study had two aims. First, we sought to investigate whether European students perceive that their peers use cannabis more frequently, and have more positive attitudes toward cannabis, compared with their personal reported cannabis use and attitudes. Second, the study aimed to investigate whether perceived peer descriptive and injunctive norms are associated with personal cannabis use and attitudes. We hypothesized that both perceived descriptive and injunctive peer norms would be associated with personal cannabis use and attitudes in European students. The data analyzed in the current study were taken from the baseline survey of the Social Norms Intervention for the prevention of Polydrug usE (SNIPE), a collaborative European feasibility study of a web-based social norms feedback intervention for polysubstance use in university students (Pischke et al., 2012).

\section{Method}

Institutional ethical approval was obtained from all sites involved in the SNIPE Project. Electronic informed consent to take part in the study was obtained from all participants before completion of the baseline survey.

\section{Participants}

The SNIPE baseline survey sampled 4,482 students enrolled at higher education institutes from seven countries in the European area. Analyses for the present study were conducted on 4,131 students ( $M_{\text {age }}=22.40$ years, $S D=4.13$ ) after the removal of participants with missing responses on the cannabis items (see Table 1 for a full summary of the sample's demographic characteristics).

\section{Measures}

Participants completed a baseline survey that included questions on their personal use of substances (alcohol, tobacco, cannabis, and other illicit substances), their personal attitudes toward the use of these substances, negative consequences associated with their personal substance use, their perceptions of the substance use and attitudes of their student peers (i.e., the perceived descriptive and injunctive norms), and their demographic characteristics. Data on alcohol, tobacco, and use of other illicit substances are reported in other articles (Helmer et al., 2014; McAlaney et al., 2015; Pischke et al., 2015). Participants rated their personal use and perceived peer use of natural forms of cannabis (e.g., marijuana, pot, hash, grass) in the past 2 months on a 10-point ordinal scale from never in my/their life to every day or nearly every day in the past 2 months. The 2-month timeframe was chosen to assess term-time use of substances (Pischke et al., 2012). Personal attitudes and perceived peer attitudes relating to the acceptability of cannabis use were rated on a five-point nominal scale from never $O K$ to use to $O K$ to use frequently if that is what the person wants to do. The baseline survey items were based on previously established measures of substance use (Humeniuk et al., 2010). The survey questions for the perceived peer descriptive and injunctive norms were institution and sex specific, requiring students to state their perceptions for the majority (i.e., $\geq 51 \%$ ) of same-sex students at their university.

\section{Procedure}

Further details of the SNIPE Project can be found in the protocol article (Pischke et al., 2012). Advertisements for the study included emails, in-class announcements, on-campus information stalls, and plasma screen notices, all of which invited students to register their email addresses on the study website, where an electronic information sheet and consent form were displayed. After consenting to participating in the study, students completed the survey items online in one sitting. The data analyzed in the current study were taken from the baseline SNIPE survey, which participants completed in the native language of their host country.

\section{Data analysis}

Descriptive analyses were conducted to calculate the percentages of students in each country who perceived that the majority of their peers used cannabis at the same, lower, or higher level compared with their own reported use and who perceived that their peers had the same, less, or more permissive attitude toward cannabis use compared with themselves. Sex differences in cannabis use were investigated using chisquare tests. 
TABLE 1. Demographic characteristics of the sample according to country $(n=4,131)$

\begin{tabular}{|c|c|c|c|c|c|c|c|}
\hline Variable & Belgium & Denmark & Germany & $\begin{array}{c}\text { Slovak } \\
\text { Republic }\end{array}$ & Spain & Turkey & $\begin{array}{l}\text { United } \\
\text { Kingdom }\end{array}$ \\
\hline$n$ & 390 & 434 & 489 & 1,816 & 171 & 735 & 96 \\
\hline \multicolumn{8}{|l|}{ Sex, \% } \\
\hline Female & 79.0 & 78.0 & 59.1 & 79.5 & 70.2 & 52.5 & 67.7 \\
\hline Male & 21.0 & 22.0 & 40.9 & 20.5 & 29.8 & 47.5 & 32.3 \\
\hline \multicolumn{8}{|l|}{ Age, in years } \\
\hline$M$ & 21.38 & 24.48 & 24.78 & 21.69 & 23.15 & 21.37 & 25.26 \\
\hline$S D$ & 4.46 & 5.75 & 4.51 & 2.18 & 6.34 & 3.23 & 9.09 \\
\hline \multicolumn{8}{|l|}{ Residence status, $\%$} \\
\hline $\begin{array}{l}\text { Living with other } \\
\text { students }\end{array}$ & 21.5 & 12.0 & 33.5 & 50.1 & 21.1 & 24.8 & 51.0 \\
\hline \multicolumn{8}{|l|}{ Year of study, \% } \\
\hline $\begin{array}{l}1 \text { st year } \\
\text { undergraduate }\end{array}$ & 32.8 & 37.1 & 20.2 & 16.5 & 18.7 & 25.3 & 39.6 \\
\hline 2nd year & 25.6 & 28.3 & 21.1 & 27.8 & 21.6 & 25.4 & 17.7 \\
\hline 3rd year & 23.1 & 12.2 & 18.8 & 14.5 & 26.3 & 25.0 & 22.9 \\
\hline Other & 4.9 & 3.9 & 22.7 & 1.3 & 21.1 & 23.7 & 3.1 \\
\hline Postgraduate & 13.6 & 18.4 & 17.2 & 39.9 & 12.3 & 0.5 & 16.7 \\
\hline \multicolumn{8}{|l|}{ Religious beliefs, \% } \\
\hline Christian & 59.5 & 55.9 & 48.1 & 81.3 & 53.2 & 0.5 & 30.5 \\
\hline Muslim & 2.6 & 1.6 & 1.6 & 0.1 & 0.6 & 84.5 & 23.2 \\
\hline Jewish & 0.5 & 0.0 & 0.2 & 0.1 & 0.0 & 0.4 & 0.0 \\
\hline Hindu & 0.0 & 0.2 & 0.0 & 0.1 & 0.6 & 0.0 & 0.0 \\
\hline Buddhist & 1.8 & 0.7 & 2.2 & 0.7 & 0.0 & 0.1 & 3.2 \\
\hline Other & 3.1 & 6.2 & 4.1 & 2.8 & 2.9 & 4.8 & 10.5 \\
\hline No religious beliefs & 32.6 & 35.3 & 43.8 & 15.0 & 42.7 & 9.7 & 32.6 \\
\hline \multicolumn{8}{|l|}{$\begin{array}{l}\text { Importance of } \\
\text { religious beliefs, \% }\end{array}$} \\
\hline Not at all important & 52.1 & 48.0 & 43.7 & 16.7 & 49.1 & 13.1 & 38.5 \\
\hline Somewhat important & 38.5 & 40.0 & 38.6 & 21.1 & 31.0 & 16.0 & 21.9 \\
\hline Important & 6.7 & 9.0 & 11.1 & 34.4 & 12.3 & 36.0 & 13.5 \\
\hline Very important & 2.8 & 3.0 & 6.6 & 27.9 & 7.6 & 34.9 & 26.0 \\
\hline
\end{tabular}

Note: Percentage data have been rounded to one decimal place, and therefore some totals may not equal 100.

Two binary logistic regressions were conducted to investigate the association between personal cannabis use (no use vs. use in the past 2 months) and personal attitudes toward cannabis use (nonpermissive vs. permissive attitudes) by perceived peer descriptive and injunctive norms. Given that responses to the cannabis use items were concentrated on 0 (i.e., non-use), we opted to dichotomize the outcome variables and analyze by binary logistic regression. The use or non-use of cannabis by students in the past 2 months and nonpermissive (never OK to use cannabis) versus permissive attitudes toward cannabis use (for responses collapsed across OK to use occasionally if it does not interfere with study or work to OK to use frequently if that is what a person wants to $d o$ ) were treated as the outcome variables for the respective models. Demographic variables, including students' age, sex, year of study, residence arrangement, religious beliefs, and importance of religious beliefs, were controlled for in the analysis, with personal cannabis use and attitudes treated as the outcome variables. Given prior research demonstrating that demographic factors such as stronger religious beliefs and living with parents and family are associated with lower likelihoods of using cannabis among students (e.g., Bell et al., 1997; Suerken et al., 2014; White et al., 2006), religious beliefs and students' residential status were included as independent categorical variables in the analyses. Personal cannabis use in the past 2 months was added as an additional independent variable when investigating the association between perceived peer attitudes with personal attitudes. Interaction terms between perceived peer norms (behaviors and attitudes for the respective analyses) with participant sex or country were also included in both models to test whether the observed associations differed by sex or country.

Given the small number of countries sampled in this study and differences in sample sizes across countries, as well as to account for the nested nature of the data, the logistic regressions were modeled with robust standard errors, which was deemed more preferable to conducting an explicit multilevel analysis (Bryan \& Jenkins, 2016; Stegmueller, 2013). Stratified analyses were conducted in which the interaction terms indicated a significant interaction between country or sex with perceived norms in predicting personal cannabis use or attitudes.

\section{Results}

Table 1 displays the demographic characteristics of the study's sample. Data analyses indicated that $8.0 \%$ of the sample reported using cannabis in the last 2 months, whereas 
TABLE 2. Personal and perceived peer cannabis use descriptive and injunctive norms at the sample level across countries $(n=4,131)$

\begin{tabular}{|c|c|c|c|c|c|c|c|c|}
\hline \multirow[b]{2}{*}{ Variable } & \multirow[b]{2}{*}{$\begin{array}{c}\text { Across } \\
\text { countries } \\
\%\end{array}$} & \multicolumn{7}{|c|}{ Country } \\
\hline & & $\underset{\%}{\text { Belgium }}$ & $\begin{array}{c}\text { Denmark } \\
\%\end{array}$ & $\begin{array}{l}\text { Germany } \\
\%\end{array}$ & $\begin{array}{c}\text { Slovak } \\
\text { Republic } \\
\%\end{array}$ & $\begin{array}{l}\text { Spain } \\
\%\end{array}$ & $\begin{array}{c}\text { Turkey } \\
\%\end{array}$ & $\begin{array}{c}\text { United } \\
\text { Kingdom } \\
\%\end{array}$ \\
\hline \multicolumn{9}{|l|}{ Descriptive norms } \\
\hline $\begin{array}{l}\text { Personally used cannabis, } \\
\text { last } 2 \text { months }\end{array}$ & 8.0 & 10.5 & 6.5 & 25.2 & 4.3 & 8.2 & 4.4 & 15.6 \\
\hline $\begin{array}{l}\text { Perceived that the majority of } \\
\text { same-sex peers use cannabis }\end{array}$ & 52.4 & 90.3 & 79.0 & 93.7 & 81.9 & 93.0 & 45.4 & 84.4 \\
\hline Injunctive norms & & & & & & & & \\
\hline Personal approval of cannabis use & 29.5 & 38.2 & 40.3 & 62.2 & 22.5 & 34.5 & 11.3 & 42.7 \\
\hline same-sex peers approve of use & 65.6 & 80.3 & 66.1 & 91.8 & 62.9 & 84.8 & 24.8 & 78.1 \\
\hline
\end{tabular}

Note: Percentage data have been rounded to one decimal place, and therefore some totals may not equal 100.

$70.4 \%$ of students reported never using cannabis in their lifetime and $21.6 \%$ reported previously using cannabis but not within the last 2 months. Across countries, the percentages of sampled students who reported recent cannabis use within the 2-month timeframe of the survey ranged from $4.3 \%$ in the Slovak Republic to $25.2 \%$ in Germany (Table 2). In terms of sex differences in cannabis use, $13.9 \%$ of male students reported using cannabis in the past 2 months compared with $6.0 \%$ of female students, $\chi^{2}(1)=78.260, p<$ .001 .

Across countries, the majority of surveyed students (52.4\%) perceived that the majority of their peers had used cannabis in the previous 2 months (Table 2). On closer inspection, the majority of students in Turkey reported not using cannabis in the last 2 months and perceived that the majority of their peers used cannabis at the same rate as themselves. However, as shown in Table 3, a substantial proportion of the Turkish sample (40.5\%) perceived that their peers had heavier cannabis consumption than themselves. In terms of attitudes toward cannabis use, the majority of students across countries reported perceiving that the ma- jority of their peers approved of cannabis use (Table 2). The percentage of surveyed students who personally reported approving of cannabis use was less than $50 \%$ of the sample from each country, except Germany. In terms of perceived peer attitudes, the majority of students in Belgium, the Slovak Republic, Spain, and the United Kingdom perceived that their peers had more permissive attitudes toward cannabis use than they themselves did (Table 3). The majority of Turkish and Danish students perceived that their peers had similar attitudes to themselves, whereas similar proportions of German students perceived that their peers had similarly permissive or more permissive attitudes toward cannabis use.

The logistic regression analyses indicated that the association between perceived peer descriptive norms with personal cannabis use was significant (odds ratio $[\mathrm{OR}]=1.42,95 \%$ CI $[1.22,1.64])$, whereas perceived peer injunctive norms were not significantly associated with personal cannabis use $(\mathrm{OR}=0.98,95 \%$ CI $[0.86,1.10])$. Perceived peer injunctive norms were significantly associated with personal attitudes $(\mathrm{OR}=1.46,95 \% \mathrm{CI}[1.09,1.94])$, as were perceived peer descriptive norms $(\mathrm{OR}=1.10,95 \% \mathrm{CI}[1.05,1.15])$ and

TABLE 3. Percentages of students with self-other discrepancies between personal use/attitudes and perceived norms across countries $(n=4,131)$

\begin{tabular}{|c|c|c|c|c|c|c|c|c|}
\hline \multirow[b]{2}{*}{ Variable } & \multirow[b]{2}{*}{$\begin{array}{c}\text { Across } \\
\text { countries } \\
\%\end{array}$} & \multicolumn{7}{|c|}{ Country } \\
\hline & & $\begin{array}{l}\text { Belgium } \\
\%\end{array}$ & $\begin{array}{c}\text { Denmark } \\
\%\end{array}$ & $\begin{array}{c}\text { Germany } \\
\%\end{array}$ & $\begin{array}{c}\text { Slovak } \\
\text { Republic } \\
\%\end{array}$ & $\begin{array}{l}\text { Spain } \\
\%\end{array}$ & $\begin{array}{c}\text { Turkey } \\
\%\end{array}$ & $\begin{array}{c}\text { United } \\
\text { Kingdom } \\
\%\end{array}$ \\
\hline \multicolumn{9}{|l|}{ Descriptive norms } \\
\hline $\begin{array}{l}\text { Perceived peer use }< \\
\text { personal use }\end{array}$ & 5.5 & 4.7 & 7.0 & 16.2 & 3.1 & 2.2 & 4.4 & 7.8 \\
\hline $\begin{array}{l}\text { Perceived peer use }= \\
\text { personal use }\end{array}$ & 27.6 & 16.8 & 36.6 & 14.9 & 22.0 & 11.6 & 55.1 & 24.5 \\
\hline $\begin{array}{l}\text { Perceived peer use }> \\
\text { personal use }\end{array}$ & 66.9 & 78.5 & 56.4 & 68.9 & 75.0 & 86.2 & 40.5 & 67.6 \\
\hline Injunctive norms & & & & & & & & \\
\hline $\begin{array}{l}\text { Perceived peer attitudes }< \\
\text { personal attitude }\end{array}$ & 6.4 & 7.2 & 9.6 & 15.2 & 3.4 & 3.5 & 6.0 & 11.0 \\
\hline $\begin{array}{l}\text { Perceived peer attitudes }= \\
\text { personal attitude }\end{array}$ & 48.4 & 37.9 & 52.3 & 38.7 & 43.6 & 29.1 & 75.9 & 38.0 \\
\hline $\begin{array}{l}\text { Perceived peer attitudes }> \\
\text { personal attitude }\end{array}$ & 45.2 & 55.0 & 38.1 & 46.0 & 53.0 & 67.4 & 18.1 & 51.0 \\
\hline
\end{tabular}

Note: Percentage data have been rounded to one decimal place, and therefore some totals may not equal 100. 
TABLE 4. Associations between perceptions of peer attitudes and cannabis use with personal cannabis use behaviors and attitudes in the past 2 months stratified by country $(n=4,131)$

\begin{tabular}{llllll}
\hline & \multicolumn{2}{c}{$\begin{array}{c}\text { Cannabis consumption } \\
\text { in past 2 months }\end{array}$} & & \multicolumn{2}{c}{$\begin{array}{c}\text { Cannabis attitude } \\
\text { (permissive) }\end{array}$} \\
\cline { 2 - 3 } \cline { 5 - 6 } Country & OR & {$[95 \% \mathrm{CI}]$} & & OR & {$[95 \% \mathrm{CI}]$} \\
\hline Slovak Republic & $1.23^{* *}$ & {$[1.07,1.42]$} & & $1.28^{* *}$ & {$[1.11,1.47]$} \\
Denmark & 1.11 & {$[0.67,1.82]$} & & $1.92^{* * *}$ & {$[1.42,2.59]$} \\
Germany & $1.20^{*}$ & {$[1.01,1.42]$} & & 1.15 & {$[0.84,1.57]$} \\
Belgium & $1.38^{*}$ & {$[1.04,1.82]$} & & $1.68^{* *}$ & {$[1.23,2.32]$} \\
Spain & $1.82^{*}$ & {$[1.12,2.95]$} & & $1.66^{*}$ & {$[1.06,2.58]$} \\
Turkey & $1.55^{*}$ & {$[1.11,2.17]$} & & $1.98^{* *}$ & {$[1.23,3.18]$} \\
United Kingdom & 1.52 & {$[0.84,2.74]$} & & 0.77 & {$[0.41,1.44]$} \\
\hline
\end{tabular}

Notes: Adjusted odds ratios (ORs) are reported controlling for participant age, sex, religious beliefs, year of study, and residence status. ORs for the personal cannabis attitude outcome also control for personal reported cannabis use behaviors. $\mathrm{CI}=$ confidence interval. ${ }^{*} p<.05 ; * * p<.01 ; * * * p<.001$.

personal cannabis use $(\mathrm{OR}=16.25,95 \%$ CI $[10.91,24.20])$. In both analyses, the association between perceived peer descriptive/injunctive norms with personal cannabis use and personal cannabis use attitudes remained significant after controlling for participant ages, sex, year of study, religious beliefs, and residential status. The association between perceived peer attitudes and personal approval of cannabis use also remained significant after controlling for personal cannabis use in the past 2 months. No significant interaction between sex and perceived descriptive $(p=.40)$ or injunctive norms $(p=.39)$ was noted for the respective models.

Significant interactions between country and perceived norms were observed for the descriptive and injunctive norm analyses $(p s<.001)$. Stratified analyses by country (Table 4) indicated that perceptions of peer cannabis use were associated with higher odds for personally using cannabis in the Slovak Republic, Germany, Belgium, Spain, and Turkey. Perceptions of peer cannabis use behaviors and peer attitudes toward cannabis use were associated with higher ORs of personally having more permissive attitudes toward cannabis use in the Slovak Republic, Denmark, Belgium, Spain, and Turkey. Estimates for the associations between perceived cannabis use norms with personal cannabis use and attitudes remained near 1 for the remaining countries.

\section{Discussion}

Perceptions of peer normative behaviors and attitudes have been associated with heavier cannabis use in North American students (e.g., Neighbors et al., 2008); however, few studies have investigated this relationship in European samples. The current study investigated whether European students perceive that their peers use cannabis more frequently and have more permissive attitudes toward cannabis use than themselves, and whether normative perceptions that the majority of peers use cannabis and approve of use are associated with personal consumption and more positive attitudes toward use. Our results indicated that students from six of the seven sampled countries, excluding Turkey, perceived that the majority of their peers had used cannabis at least once in the past 2 months. A high proportion of students across countries, again excluding Turkey, thought that the majority of their peers had permissive attitudes toward the use of cannabis. The majority of students across countries perceived that their peers used cannabis more than they did and had similar or more permissive attitudes toward cannabis than their own reported behaviors and attitudes.

Based on the logistic regression analyses, perceived peer cannabis use and approving attitudes were associated with personal cannabis use and positive cannabis use attitudes while controlling for participants' ages, year of study, residential status, and religious beliefs. Although there were intercountry differences in cannabis use and perceived norms, it was notable that the majority of Turkish students reported accurate perceptions of their peers' cannabis use behaviors and attitudes compared to actual reported rates. In contrast to other sites, the Turkish sample included a majority of Muslim students (70.9\%), who rated their religious beliefs as being important or very important. It may be that the lack of normative misperceptions in the Turkish sample relates to the inclusion of individuals with strong religious beliefs, and possibly wider campus norms of participation in religion, which can act as a protective factor against cannabis use (Bell et al., 1997; Suerken et al., 2014). Furthermore, a majority of the German students reported that they personally approved of cannabis use, whereas the majority of students at the other sites reported that they did not approve of cannabis use, which may reflect more liberal local attitudes toward cannabis use among German students.

The current study's results are consistent with North American studies demonstrating that students overestimate their peers' cannabis use behaviors and attitudes and that normative perceptions are predictive of personal cannabis use behaviors and attitudes (Arbour-Nicitopoulos et al., 2010; Bertholet et al., 2013; Kilmer et al., 2006; LaBrie et al., 2009; Martens et al., 2006; Neighbors et al., 2013; Page 
\& Scanlan, 2000). Our findings are also in line with data showing similar associations between European students' personal and perceived peer use and attitudes toward using other illicit substances (including cocaine, methylenedioxymethamphetamine [MDMA; Ecstasy], and amphetamines) (Helmer et al., 2014), alcohol (e.g., McAlaney et al., 2015), and tobacco (Pischke et al., 2015).

Compared with the perceived social norms associated with student alcohol and tobacco use, the perceived norms associated with student cannabis use are likely to be different because of the illicit status of cannabis. Alcohol consumption is a relatively common public and visible behavior on most European university campuses, whereas cannabis, in contrast, is typically a controlled illicit substance. Cannabisusing students may therefore engage in cannabis consumption in smaller, closed friendship groups in less visible and nonpublic settings compared with when they consume alcohol. The perceived social norms of closer friendship groups, family members, and other users may be more influential on personal cannabis use behaviors compared with the perceived norms of the majority of the student population. Indeed, a limitation of the present study is the use of the wider same-sex student population as the normative reference group, particularly as recent work has indicated that perceived descriptive and injunctive norms for friends are stronger predictors of students' personal cannabis use than typical student norms (Buckner, 2013; Lewis \& Clemens, 2008). Furthermore, empirical research has suggested that U.S. students with heavier rates of cannabis use perceive that both their close peers and their parents are more approving of cannabis use (LaBrie et al., 2011), highlighting the potential power of more proximal normative feedback messages on personal cannabis use. There is also evidence to suggest that students who use cannabis more heavily may identify more with typical students than other users (Neighbors et al., 2013), suggesting that students' social identification with other cannabis users may vary according to their own usage. Therefore, normative feedback may need to be tailored for students' own usage, and possibly the degree of identification with the wider social group, to ensure that the relevant discrepancies between personal behaviors and perceived peer norms are highlighted. The proximity of reference groups featured in normative feedback may be important for cannabis use interventions focused on correcting perceived peer behaviors and attitudes, such as those based on the social norms approach (McAlaney et al., 2011). There is, however, a lack of European-based research investigating the predictive power of close friend norms versus typical student norms in predicting student cannabis use.

There are some limitations associated with the current study. The analyses were based on self-reported cannabis use; therefore, over- and underreporting by students cannot be ruled out. That being said, participants completed a confidential web-based survey that allowed them to answer questions on sensitive issues, such as illicit substance use, thereby minimizing perceived pressures to provide socially desirable responses on the survey compared with testing in laboratory settings or in classes. There were some differences in sample sizes, because study sites differed in their ability to access the local student population. Furthermore, the current analysis used a cross-sectional design and cannot elucidate whether normative perceptions may predict future patterns of cannabis use or vice versa. The relationship between perceived norms and cannabis use may be a reciprocal one, as suggested by prior alcohol norms research (Neighbors et al., 2006).

In conclusion, the results of the current study support previous research into the relationship between perceived peer behaviors and attitudes toward substance use with personal use and attitudes. This is the first study to report such associations in relation to cannabis use among a large multinational sample of European students. Interventions focused on harm prevention, such as those based on the social norms approach, may be effective in challenging discrepancies between personal behaviors/attitudes and perceived peer norms and may assist in preventing and reducing cannabis use among student populations.

\section{Conflict of Interest Statement}

Bridgette M. Bewick, as keynote speaker/expert advisor, has received reimbursement of travel expenses and/or time from Anheuser-Busch, Noctis, and the International Centre for Alcohol Polices. She has been a recipient of a research grant provided by the European Research Advisory Board (ERAB) and is currently a recipient of a research grant provided by the International Alliance for Responsible Drinking. John McAlaney has received a travel grant from ERAB. Rafael T. Mikolajczyk received research grants from Sanofi Pasteur MSD and Bayer Pharma. The projects were not related to the current study. Christiane Stock received funding from Trygfonden (Denmark) for a similar study that is unrelated to the present study. The other authors have no conflicts of interest to report.

\section{References}

Arbour-Nicitopoulos, K. P., Kwan, M. Y. W., Lowe, D., Taman, S., \& Faulkner, G. E. J. (2010). Social norms of alcohol, smoking, and marijuana use within a Canadian university setting. Journal of American College Health, 59, 191-196. doi:10.1080/07448481.2010.502194

Arria, A. M., Caldeira, K. M., O’Grady, K. E., Vincent, K. B., Fitzelle, D. B., Johnson, E. P., \& Wish, E. D. (2008). Drug exposure opportunities and use patterns among college students: Results of a longitudinal prospective cohort study. Substance Abuse, 29, 19-38. doi:10.1080/08897070802418451

Bell, R., Wechsler, H., \& Johnston, L. D. (1997). Correlates of college student marijuana use: Results of a US National Survey. Addiction, 92, 571-581. doi:10.1111/j.1360-0443.1997.tb02914.x

Bertholet, N., Faouzi, M., Studer, J., Daeppen, J.-B., \& Gmel, G. (2013). Perception of tobacco, cannabis, and alcohol use of others is associated with one's own use. Addiction Science \& Clinical Practice, 8, 15. doi:10.1186/1940-0640-8-15

Bryan, M. L., \& Jenkins, S. P. (2016). Multilevel modelling of country effects: A cautionary tale. European Sociological Review, 32, 3-22. doi:10.1093/esr/jcv059 
Buckner, J. D. (2013). College cannabis use: The unique roles of social norms, motives, and expectancies. Journal of Studies on Alcohol and Drugs, 74, 720-726. doi:10.15288/jsad.2013.74.720

Caldeira, K. M., Arria, A. M., O’Grady, K. E., Vincent, K. B., \& Wish, E. D. (2008). The occurrence of cannabis use disorders and other cannabisrelated problems among first-year college students. Addictive Behaviors, 33, 397-411. doi:10.1016/j.addbeh.2007.10.001

Caldeira, K. M., O’Grady, K. E., Vincent, K. B., \& Arria, A. M. (2012). Marijuana use trajectories during the post-college transition: Health outcomes in young adulthood. Drug and Alcohol Dependence, 125, 267-275. doi:10.1016/j.drugalcdep.2012.02.022

Degenhardt, L., Chiu, W.-T., Sampson, N., Kessler, R. C., Anthony, J. C., Angermeyer, M., . . . Wells, J. E. (2008). Toward a global view of alcohol, tobacco, cannabis, and cocaine use: Findings from the WHO World Mental Health Surveys. PLoS Medicine, 5, e141. doi:10.1371/ journal.pmed.0050141

Degenhardt, L., \& Hall, W. (2012). Extent of illicit drug use and dependence, and their contribution to the global burden of disease. The Lancet, 379, 55-70. doi:10.1016/S0140-6736(11)61138-0

Ecker, A. H., Richter, A. A., \& Buckner, J. D. (2014). Cannabis-related impairment: The impacts of social anxiety and misconceptions of friends' cannabis-related problems. Addictive Behaviors, 39, 1746-1749. doi:10.1016/j.addbeh.2014.07.004

Elliott, J. C., \& Carey, K. B. (2012). Correcting exaggerated marijuana use norms among college abstainers: A preliminary test of a preventive intervention. Journal of Studies on Alcohol and Drugs, 73, 976-980. doi:10.15288/jsad.2012.73.976

Franca, L. R., Dautzenberg, B., Falissard, B., \& Reynaud, M. (2010). Peer substance use overestimation among French university students: A cross-sectional survey. BMC Public Health, 10, 169. doi:10.1186/1471-2458-10-169

Grant, J. E., Chamberlain, S. R., Schreiber, L., \& Odlaug, B. L. (2012). Neuropsychological deficits associated with cannabis use in young adults. Drug and Alcohol Dependence, 121, 159-162. doi:10.1016/j. drugalcdep.2011.08.015

Hall, W. (2009). The adverse health effects of cannabis use: What are they, and what are their implications for policy? International Journal on Drug Policy, 20, 458-466. doi:10.1016/j.drugpo.2009.02.013

Hall, W., \& Degenhardt, L. (2009). Adverse health effects of nonmedical cannabis use. The Lancet, 374, 1383-1391. doi:10.1016/ S0140-6736(09)61037-0

Hammersley, R., \& Leon, V. (2006). Patterns of cannabis use and positive and negative experiences of use amongst university students. Addiction Research and Theory, 14, 189-205. doi:10.1080/16066350500453309

Hawkins, J. D., Catalano, R. F., \& Miller, J. Y. (1992). Risk and protective factors for alcohol and other drug problems in adolescence and early adulthood: Implications for substance abuse prevention. Psychological Bulletin, 112, 64-105. doi:10.1037/0033-2909.112.1.64

Helmer, S. M., Mikolajczyk, R. T., McAlaney, J., Vriesacker, B., van Hal, G., Akvardar, Y., . . . Zeeb, H. (2014). Illicit substance use among university students from seven European countries: A comparison of personal and perceived peer use and personal and perceived peer attitudes towards illicit substance use. Preventive Medicine, 67, 204-209. doi:10.1016/j.ypmed.2014.07.039

Humeniuk, R. E., Henry-Edwards, S., Ali, R. L., Poznyak, V., \& Monteiro, M. (2010). The Alcohol, Smoking and Substance Involvement Screening Test (ASSIST): Manual for use in primary care. Geneva, Switzerland: World Health Organization. Retrieved from http://apps.who.int/iris/bitst ream/10665/44320/1/9789241599382_eng.pdf

Kilmer, J. R., Walker, D. D., Lee, C. M., Palmer, R. S., Mallett, K. A., Fabiano, P., \& Larimer, M. E. (2006). Misperceptions of college student marijuana use: Implications for prevention. Journal of Studies on Alcohol, 67, 277-281. doi:10.15288/jsa.2006.67.277
LaBrie, J. W., Grossbard, J. R., \& Hummer, J. F. (2009). Normative misperceptions and marijuana use among male and female college athletes. Journal of Applied Sport Psychology, 21, Supplement 1, S77-S85. doi:10.1080/10413200802582839

LaBrie, J. W., Hummer, J. F., \& Lac, A. (2011). Comparing injunctive marijuana use norms of salient reference groups among college student marijuana users and nonusers. Addictive Behaviors, 36, 717-720. doi:10.1016/j.addbeh.2011.02.004

LaBrie, J. W., Hummer, J. F., Lac, A., \& Lee, C. M. (2010). Direct and indirect effects of injunctive norms on marijuana use: The role of reference groups. Journal of Studies on Alcohol and Drugs, 71, 904-908. doi:10.15288/jsad.2010.71.904

Le Strat, Y., Ramoz, N., Horwood, J., Falissard, B., Hassler, C., Romo, L., ... Gorwood, P. (2009). First positive reactions to cannabis constitute a priority risk factor for cannabis dependence. Addiction, 104, 1710-1717. doi:10.1111/j.1360-0443.2009.02680.x

Lee, C. M., Neighbors, C., Kilmer, J. R., \& Larimer, M. E. (2010). A brief, web-based personalized feedback selective intervention for college student marijuana use: A randomized clinical trial. Psychology of Addictive Behaviors, 24, 265-273. doi:10.1037/a0018859

Lewis, T. F., \& Clemens, E. (2008). The influence of social norms on college student alcohol and marijuana use. Journal of College Counseling, 11, 19-31. doi:10.1002/j.2161-1882.2008.tb00021.x

Martens, M. P., Page, J. C., Mowry, E. S., Damann, K. M., Taylor, K. K., \& Cimini, M. D. (2006). Differences between actual and perceived student norms: An examination of alcohol use, drug use, and sexual behavior. Journal of American College Health, 54, 295-300. doi:10.3200/ JACH.54.5.295-300

McAlaney, J., Bewick, B., \& Hughes, C. (2011). The international development of the 'Social Norms' approach to drug education and prevention. Drugs: Education, Prevention \& Policy, 18, 81-89. doi:10.3109/09687631003610977

McAlaney, J., Helmer, S. M., Stock, C., Vriesacker, B., Van Hal, G., Dempsey, R. C., . . Mikolajczyk, R. (2015). Personal and perceived peer use of and attitudes toward alcohol among university and college students in seven EU countries: Project SNIPE. Journal of Studies on Alcohol and Drugs, 76, 430-438. doi:10.15288/jsad.2015.76.430

Moore, T. H. M., Zammit, S., Lingford-Hughes, A., Barnes, T. R. E., Jones, P. B., Burke, M., \& Lewis, G. (2007). Cannabis use and risk of psychotic or affective mental health outcomes: A systematic review. The Lancet, 370, 319-328. doi:10.1016/S0140-6736(07)61162-3

Neighbors, C., Dillard, A. J., Lewis, M. A., Bergstrom, R. L., \& Neil, T. A. (2006). Normative misperceptions and temporal precedence of perceived norms and drinking. Journal of Studies on Alcohol, 67, 290-299. doi:10.15288/jsa.2006.67.290

Neighbors, C., Foster, D. W., Walker, D. D., Kilmer, J. R., \& Lee, C. M. (2013). Social identity as a moderator of the association between perceived norms and marijuana use. Journal of Studies on Alcohol and Drugs, 74, 479-483. doi:10.15288/jsad.2013.74.479

Neighbors, C., Geisner, I. M., \& Lee, C. M. (2008). Perceived marijuana norms and social expectancies among entering college student marijuana users. Psychology of Addictive Behaviors, 22, 433-438. doi:10.1037/0893-164X.22.3.433

Neighbors, C., Lewis, M. A., Atkins, D. C., Jensen, M. M., Walter, T., Fossos, N., . . L Larimer, M. E. (2010). Efficacy of web-based personalized normative feedback: A two-year randomized controlled trial. Journal of Consulting and Clinical Psychology, 78, 898-911. doi:10.1037/ a0020766

Page, R. M., \& Roland, M. (2004). Misperceptions of the prevalence of marijuana use among college students: Athletes and non-athletes. Journal of Child \& Adolescent Substance Abuse, 14, 61-75. doi:10.1300/ J029v14n01_04

Page, R. M., \& Scanlan, A. (2000). Perceptions of the prevalence of Mari- 
juana use among college students: A comparison between current users and nonusers. Journal of Child \& Adolescent Substance Abuse, 9, 1-12. doi:10.1300/J029v09n02_01

Perkins, H. W., Meilman, P. W., Leichliter, J. S., Cashin, J. R., \& Presley, C. A. (1999). Misperceptions of the norms for the frequency of alcohol and other drug use on college campuses. Journal of American College Health, 47, 253-258. doi:10.1080/07448489909595656

Pischke, C. R., Helmer, S. M., McAlaney, J., Bewick, B. M., Vriesacker, B., Van Hal, G., . . Z Zeeb, H. (2015). Normative misperceptions of tobacco use among university students in seven European countries: Baseline findings of the 'Social Norms Intervention for the prevention of Polydrug usE' study. Addictive Behaviors, 51, 158-164. doi:10.1016/j. addbeh.2015.07.012

Pischke, C. R., Zeeb, H., van Hal, G., Vriesacker, B., McAlaney, J., Bewick, B. M., . . Mikolajczyk, R. T. (2012). A feasibility trial to examine the social norms approach for the prevention and reduction of licit and illicit drug use in European University and college students. BMC Public Health, 12, 882. doi:10.1186/1471-2458-12-882

Skinner, R., Conlon, L., Gibbons, D., \& McDonald, C. (2011). Cannabis use and non-clinical dimensions of psychosis in university students presenting to primary care. Acta Psychiatrica Scandinavica, 123, 21-27. doi:10.1111/j.1600-0447.2010.01546.x
Smart, R. G., \& Ogborne, A. C. (2000). Drug use and drinking among students in 36 countries. Addictive Behaviors, 25, 455-460. doi:10.1016/ S0306-4603(99)00013-1

Stegmueller, D. (2013). How many countries for multilevel modeling? A comparison of frequentist and Bayesian approaches. American Journal of Political Science, 57, 748-761. doi:10.1111/ajps.12001

Suerken, C. K., Reboussin, B. A., Sutfin, E. L., Wagoner, K. G., Spangler, J., \& Wolfson, M. (2014). Prevalence of marijuana use at college entry and risk factors for initiation during freshman year. Addictive Behaviors, 39, 302-307. doi:10.1016/j.addbeh.2013.10.018

Webb, E., Ashton, C. H., Kelly, P., \& Kamali, F. (1996). Alcohol and drug use in UK university students. The Lancet, 348, 922-925. doi:10.1016/ S0140-6736(96)03410-1

White, H. R., McMorris, B. J., Catalano, R. F., Fleming, C. B., Haggerty, K. P., \& Abbott, R. D. (2006). Increases in alcohol and marijuana use during the transition out of high school into emerging adulthood: The effects of leaving home, going to college, and high school protective factors. Journal of Studies on Alcohol, 67, 810-822. doi:10.15288/ jsa.2006.67.810

World Health Organization. (1997). Cannabis: A health perspective and research agenda. Geneva, Switzerland: Author. Retrieved from http:// apps.who.int/iris/bitstream/10665/63691/1/WHO_MSA_PSA_97.4.pdf 